\section{Mentha longifolia (L.) L.: A Model Species for Mint Genetic Research}

\author{
K.J. Vining, Q. Zhang, A.O. Tucker, C. Smith, and T.M. Davis \\ University of New Hampshire, Department of Plant Biology, 46 College Road, \\ Rudman Hall, Durham, NH 03824
}

\begin{abstract}
Mentha longifolia, a wild relative of the polyploid, cultivated Mentha (mint) species, was evaluated as a potential model system for genetic research relevant to the cultivated mints. Fourteen Mentha longifolia accessions maintained by the US Department of Agriculture (USDA), Agricultural Research Service, National Clonal Germplasm Repository (NCGR), were highly diverse with respect to geographic origin, oil composition, verticillium wilt resistance, aspects of morphology, and molecular marker polymorphism. Accession CMEN 584 was the only carvone chemotype, while CMEN 682 was the only accession with high menthol content. Trans-piperitone oxide was the primary oil component of accessions CMEN 17 and CMEN 18, while pulegone was most abundant in CMEN 20, CMEN 500, CMEN 501, and CMEN 585. Four accessions-CMEN 585, CMEN 17, CMEN 501, and CMEN 81-were consistently resistant to verticillium wilt, while CMEN 584 and CMEN 516 were highly susceptible. Pairwise similarity coefficients were calculated and a UPGMA (unweighted pair-group analysis) tree was constructed on the basis of 63 informative randomly amplified polymorphic DNA (RAPD) marker bands. CMEN 585 and CMEN 584 shared the greatest number of bands (16), and formed a distinct cluster in the UPGMA tree. Seven pairs of accessions had no bands in common, emphasizing the high degree of molecular diversity represented by these accessions. The favorable features of diploid $(2 \mathrm{n}=\mathbf{2 x}=\mathbf{2 4})$ genome constitution, comparatively small genome size (400 to $500 \mathrm{Mb}$ ), self-fertility, fecundity, and diversity with respect to economically relevant traits, contribute to $M$. longifolia's potential usefulness as a model system for the cultivated mints. As a perennial species amenable to vegetative propagation, M. longifolia's spectrum of susceptibility/resistance to an important vascular wilt disease encourages its further evaluation as a system for broader studies of plant-microbe interactions and disease resistance mechanisms.
\end{abstract}

The principal Mentha $($ Lamiaceae $=\operatorname{mint}$ family) species of commerce in the United States are vegetatively propagated polyploids, making them difficult or intractable subjects for transmission genetic analysis and conventional breeding. Native spearmint (Mentha $\times$ villosonervata Opiz) is triploid $(2 n=3 x=36)$, although morphologically similar to fertile, tetraploid spearmint (M. spicata L., $2 n=4 x=48$ ). Scotch spearmint $(M . \times$ gracilis Sole $)$ is heptaploid $(2 n$ $=7 x=84)$. 'Mitcham'peppermint $(M$. $\times$ piperita L.) is hexaploid $(2 n=6 x=72)$ (Tucker and Naczi, 2005; Tucker and Fairbrothers, 1990; Udo etal., 1962). Polyploidy increases composite genome size and allelic complexity, hampering structural and functional genomics studies, and may be accompanied by poor fertility. Not surprisingly, no genetic linkage maps have been constructed for Mentha. Other than an extensive literature on the genetics of oil quality, both classical (Hefendehl and Murray, 1976; Hendriks et al., 1976) and molecular (Croteau and Gershenzon, 1994), few traits have been characterized

Received for publication 12 Dec. 2004. Accepted for publication 25 Mar. 2005. We gratefully acknowledge Sara Olson for helping to develop the verticillium resistance screening protocol. We also thank Dennis Johnson and Linda Ciuffetti for providing $V$. dahliae cultures, and J. Brent Loy and Rosanna Freyre for helpful comments on the manuscript. This is Scientific Contribution 2267 from the New HampshireAgricultural Experiment Station(NHAES). This research was supported in part by NHAES Project $\mathrm{H} 433$, and grants from the Mint Industry Research Council. genetically, and few genomic resources have been developed. Gene identification in Mentha has been limited to genes encoding enzymes involved in essential oil biosynthesis. These genes have been extensively characterized, and genetic manipulation of peppermint oil biosynthesis has been initiated (Mahmoud et al., 2004; Burke et al., 2004; Mahmoud and Croteau, 2001).

A diverse and widely distributed Mentha germplasm base has been documented (Tucker and Naczi, 2005). As of December 2004, the NCGR in Corvallis, Ore., maintained 441 Mentha accessions as vegetative clones and 52 as seed, representing 20 species and a diversity of interspecific hybrids (GRIN). Twenty-one accessions are $M$. longifolia, and six are listed as $M$. longifolia $\times M$. longifolia hybrids. In addition, of the 67 accessions listed as simply Mentha hybrid, 30 include $M$. longifolia in the known or inferred pedigree. The USDA collection of M. longifolia accessions represents a wide range of geographic, phenotypic, and genetic diversity.

Mentha longifolia has the widest natural geographic distribution of any Mentha species, from western Europe to central Asia and in southernAfrica. Itmay encompass 22 subspecies (Tucker and Naczi, 2005). Almost all are diploid $(2 n=2 x=24)$, but some tetraploid $(2 n=4 x=$ 48) forms have also been described (Chambers and Hummer, 1994). The sexual fertility of the diploid, and even the tetraploid, forms has been documented (Fagbemi and Morton, 1982; Murray, 1960). The size of the M. longifolia genome was reported as $1 \mathrm{C}=385 \mathrm{Mbp}$ (Bennett and Leitch, 2005), and in the range of $2 \mathrm{C}$ $=0.84$ to $0.99 \mathrm{pg}$ (Gobert et al., 2002), or $1 \mathrm{C}$ $=405$ to $477 \mathrm{Mbp}$. The M. longifolia $\mathrm{C}$ value is relatively small among those of cultivated plants, being comparable to that of rice $(\mathrm{C}=$ 400 to $466 \mathrm{Mbp}$ ) and about half that of tomato $(\mathrm{C}=980 \mathrm{Mbp})$ (Bennett and Leitch, 2005). Phylogenetic analysis of Mentha indicates that $M$. longifolia is an ancestor of M. spicata, and may be the latter's organelle genome source (Bunsawat et al., 2004). In turn, M. spicata is a parent of $M$. × gracilis and of $M$. × piperita (Tucker and Naczi, 2005; Tucker et al., 1991; Tucker and Fairbrothers, 1990). Mentha canadensis is believed to have arisen as a hybrid of M. longifolia and M. arvensis (Tucker and Chambers, 2002).

We have examined a set of $M$. longifolia accessions maintained by the NCGR, with particular attention to two traits of economic relevance: oil composition and resistance to verticillium wilt, an important disease of peppermint. This paper documents the phenotypic and genetic diversity among these $M$. longifolia accessions and reviews the features that make M. longifolia a potentially useful model species for Mentha genetic and genomic research.

\section{Materials and Methods}

Germplasm. Fourteen accessions initially identified as $M$. longifolia, including 4 subspecies, were obtained as rooted plants or rhizomes from the NCGR. The USDANational Plant Germplasm System Plant Information (PI) numbers for each of these accessions, as well as their chromosome numbers (if known) and geographic origins, are listed in Table 1. Plants were maintained in a greenhouse at the University of New Hampshire in 22-cm pots, and were propagated vegetatively. Observations of morphology were made by direct visual examination and by light microscopy.

Oil composition. Oils from whole flowering plants were distilled with a neo-Clevenger of Moritz after Kaiser and Lang with the modification of Hefendehl (Kaiser and Lang, 1951; von Rudloff, 1969). Mass spectrawere recorded with a 5970 Hewlett-Packard Mass Selective detector coupled to a HP $5890 \mathrm{GC}$ using a HP $50 \mathrm{~m} \times 0.2$ $\mathrm{mm}$ fused silica column coated with $0.33 \mathrm{~mm}$ FFAP(crosslinked). The GC was operated under the following conditions: injector temperature $250{ }^{\circ} \mathrm{C}$; oven temperature programmed to 60 ${ }^{\circ} \mathrm{C}$ held for $1 \mathrm{~min}$ to $115^{\circ} \mathrm{C}$ at $2.5^{\circ} \mathrm{C}$ per min, then to $210^{\circ} \mathrm{C}$ at $1.0^{\circ} \mathrm{C}$ per min and held for $30 \mathrm{~min}$; injection size $1 \mathrm{~mL}$ (about $50 \%$ solution in spectroscopy grade n-pentane) split 1:10. The MSD EI was operated at electron impact source $70 \mathrm{eV}, 250^{\circ} \mathrm{C}$. Identifications were made by Kovats Indices and library searches of our volatile oil library supplemented with those of NBS, NIST, and Wiley.

Verticillium resistance screening. Qualitative assessment of verticillium resistance in all 14 accessions was conducted with a wild-type Verticillium dahliae strain provided by Dennis Johnson at Washington State University. Based on the outcome of these initial trials, a subset of resistant and susceptible accessions was chosen 
Table 1. Features of Mentha longifolia accessions used in this study. Accession numbers, status and geographic origin as listed on http://www.ars-grin.gov/cor/ mentha/meninfo.html.

\begin{tabular}{|c|c|c|c|}
\hline Accession & Status & $2 n^{z}$ & Collected from \\
\hline CMEN 17 (PI 557755) & Breeding material & 24 & Unknown European country \\
\hline CMEN 18 (PI 557756) & Wild material & 24 & Netherlands \\
\hline CMEN 19 (PI 557757) & Wild material & 24 & France \\
\hline CMEN 20 (PI 557770) & Wild material & 24 & Syria \\
\hline CMEN 34 (PI 557758) & Wild material & $---y^{y}$ & India \\
\hline CMEN 500 (PI 212313) & Wild material & 48 & Afghanistan \\
\hline CMEN 501 (PI 212314) & Cultivated material & 48 & Afghanistan \\
\hline CMEN 516 (PI 557760) & Cultivated material & --- & Italy \\
\hline CMEN 584 (PI 557769) & Uncertain improvement status & 24 & South Africa \\
\hline CMEN 585 (PI 557767) & Uncertain improvement status & 24 & South Africa \\
\hline CMEN 592 (PI 557766) & Wild material & 24 & Uzbekistan \\
\hline CMEN 635 (PI 557768) & Wild material & 24 & Nepal \\
\hline CMEN 682 (PI617491) & Cultivar: 'Velvet' & --- & Russia \\
\hline CMEN 81 (PI 557759) & Probable hybrid of $M$. longifolia $\times M$. spicata & --- & United States \\
\hline
\end{tabular}

${ }^{\mathrm{z} C h a m b e r s ~ a n d ~ H u m m e r ~(1994) . ~}$

y Undetermined chromosome number.

for closer examination and for use as crossing parents for future genetic studies. The latter trials differed from the initial assessments in that a quantitative rating scale was used, and a $V$. dahliae strain which was transformed with green fluorescent protein (GFP) (Lorang et al., 2001), provided by Linda Ciuffetti at Oregon State University, was used instead of the wild-type strain. Both $V$. dahliae cultures were maintained in petri plates on Czapek-Dox medium, which was supplemented with $45 \mu \mathrm{g} \cdot \mathrm{mL}^{-1}$ hygromycin for the GFP strain.

Mentha longifolia cuttings of uniform size were rooted in 1206 cell packs with soilless Metro Mix 360 (The Scotts Co., Maryville, Ohio). They were maintained for 2 weeks in a growth chamber with fluorescent lighting ( $15 \pm$ $\left.3 \mu \mathrm{mol} \cdot \mathrm{m}^{-2} \cdot \mathrm{s}^{-1}\right)$, cool temperatures and a shortday cycle $\left(22^{\circ} \mathrm{C}, 10 \mathrm{~h} \mathrm{light} / 20^{\circ} \mathrm{C}, 14 \mathrm{~h}\right.$ dark $)$ to minimize growth and prevent flowering.

Screening was performed using a modified root-dip inoculation technique based on that of Green and Simon (1996). An appropriate volume of Verticillium in liquid Czapek-dox medium was incubated at room temperature on a shaker for 1 to 2 weeks. The volume of liquid culture used depended on the number of cuttings to be inoculated. Liquid cultures were strained through a single layer of Miracloth to separate conidia from hyphae. The filtrate was centrifuged at $10,000 g_{n}$ for 5 min to pellet conidia. Pellets were resuspended in 100 $\mathrm{mL}$ distilled $\mathrm{H}_{2} \mathrm{O}$. This step was performed to eliminate any residual medium as well as any substances secreted by the fungus. A hemacytometer was used to count conidia with a compound microscope $(20 \times$ objective). The conidial suspension was diluted with distilled $\mathrm{H}_{2} \mathrm{O}$ to about $10^{7}$ conidia/mL.

Screening trials had 12 replicate cuttings randomized within each treatment (control, inoculated). Control plants and inoculated plants were processed simultaneously. Cuttings were uprooted, soil was shaken from roots, and plants were placed in 50-mL beakers containing about $20 \mathrm{~mL}$ of either distilled $\mathrm{H}_{2} \mathrm{O}$ (uninoculated control) or conidial suspension for $5 \mathrm{~min}$. Plants were then replanted in new flats in Metro Mix 360. After inoculation, plants were kept in the growth chamber with minimal watering, continuing the aforementioned light and temperature conditions. After 2 weeks, plants were moved to the greenhouse under natural light and ambient temperature.

Observations were taken 8 weeks postinoculation. For plants with dead primary stems, stem sections were surface-sterilized and plated on water agar to confirm the presence of Verticillium dahliae. Degree of plant stunting, horizontal leaf curling (crescent leaf), and tissue chlorosis and necrosis were all observed in order to assign an overall symptom severity rating from 0 to 4 (Dennis Johnson, personal communication). A0 rating indicated lack of visible symptoms; a 4 rating meant the plant was dead. Intermediate ratings described plants with mild to severe symptoms. Ratings data for inoculated plants were processed in Systat v.10.0 by ANOVA as a completely randomized design. Pairwise comparisons were made with Tukey's tests.

DNA extraction. DNA was extracted from fresh, unexpanded leaf tissue using the CTAB miniprep method of Torres et al. (1993), with the following modifications: sodium bisulphate was not used in the grinding buffer, chloroform-octanol was not added to the grinding slurry before $65^{\circ} \mathrm{C}$ incubation, and the ethanol wash utilized $70 \%$ ethanol without sodium acetate. Concentration of DNA dissolved in $50 \mu \mathrm{L}$ TE (Tris-EDTA, pH 8.0) was measured fluorometrically, then DNA was diluted with sterile $\mathrm{H}_{2} \mathrm{O}$ to a standard stock concentration of $40 \mathrm{ng} \cdot \mu \mathrm{L}^{-1}$.

Polymerase chain reaction. Fourteen oligonucleotide primers (Operon technologies, Alameda, Calif.) were used individually in PCR to detect randomly amplified polymorphic DNA (RAPD) polymorphisms. DNA was amplified in $25 \mu$ L reactions using $100 \mathrm{ng}$ template DNA, 0.1UTaq DNA polymerase(Eppendorf), $2.5 \mathrm{mM}$ each of dNTP (Promega) and $0.8 \mu \mathrm{M}$ primer. The reactions were performed in a thermal cycler programmed for one cycle of $2 \mathrm{~min}$ at $94{ }^{\circ} \mathrm{C}$ followed by 39 cycles of $1 \mathrm{~min}$ at $94^{\circ} \mathrm{C}$, $2 \mathrm{~min} 30 \mathrm{~s}$ at $35^{\circ} \mathrm{C}, 30 \mathrm{~s}$ at $45^{\circ} \mathrm{C}$, and a final elongation step of $10 \mathrm{~min}$ at $72^{\circ} \mathrm{C}$.

Separation and visualization of amplification products. PCR products were separated on gels containing 1\% NuSieve GTG agarose (FMC Bioproducts, Rockland, Maine) and 1\% agarose (Shelton Scientific, Shelton, Conn.) run in $1 \times$ TBE, pH 8.0 at $90 \mathrm{~V}$ for at least $3.5 \mathrm{~h}$ at $4{ }^{\circ} \mathrm{C}$. Gels were stained with ethidium bromide and photographed under UV light.
RAPD marker diversity analysis. Only informative markers (bands that were present in at least two accessions and absent in at least two) were included in the analysis. A total of 63 bands were treated in a binary format and scored as 1 (band present) or 0 (band absent). Pairwise genetic similarities were calculated using the Jaccard similarity coefficient $(\mathrm{a} /(\mathrm{a}$ $+\mathrm{b}+\mathrm{c})$ ) (Jaccard, 1908). Additionally, a phenetic analysis was conducted using Paup $4.0 \mathrm{~b} 10$. A dendrogram was generated using the unweighted pair-group method with arithmetic averages(UPGMA) method with 1000 bootstrap replications.

Genome size determination. Root tips were fixed in Farmer's solution (3 ethanol:1 glacial acetic acid) and sent to I.J. Leitch, Jodrell Laboratory, Royal Botanic Gardens, Kew, where the $\mathrm{C}$ values were measured by Feulgen microdensitometry (Bennett and Leitch, 2005).

\section{Results}

Among the morphological characters showing variation were leaf shape, flower color(Table 2) and growth habit. CMEN 584 and CMEN 585 had lanceolate leaves; the others' leaves were ovate(Table 2). Three accessions - CMEN 584, CMEN 585 and CMEN 34-had white flowers, while flowers of the other accessions were various shades of purple. Under the growth conditions in the UNH greenhouse, CMEN 584 and CMEN 585 had a tall upright growth habit, reaching a height of about $100 \mathrm{~cm}$ at flowering. CMEN 682 and CMEN 34 had a moderately upright growth habit, but only reached $50 \%$ to $75 \%$ of the height of CMEN 584 and CMEN 585 . The other accessions had a shorter upright growth habit.

Oil composition was highly variable among the accessions (Table 2). Pulegone was the principal oil component of CMEN 20, CMEN 500, CMEN 501, and CMEN 585. These accessions, along with CMEN 682 and CMEN81, contained moderate levels of menthone. CMEN 17, CMEN 18, and CMEN 635 had high levels of cis- or trans-piperitone oxide. CMEN 584 was the only accession for which the principal oil component was carvone.

The M. longifolia germplasm showed diversity in response to inoculation with $V$. dahliae. Symptoms first became apparent 2 to 4 weeks 
Table 2. Phenotypes of Mentha longifolia accessions. Only principal oil compounds (>5\%) are listed. Verticillium resistance qualitative ratings are from initial screenings conducted with wild type Verticillium dahliae before a numerical rating system was implemented. Qualitative ratings are $\mathrm{R}=$ resistant, $\mathrm{I}=$ intermediate, $\mathrm{S}=$ susceptible. Quantitative ratings are from subsequent screenings of a subset of accessions chosen as crossing parents for future genetic studies. The latter trials were conducted with a GFP-transformed $V$. dahliae strain. Ratings are average scores for total numbers of plants screened for each genotype. The rating system is $0=$ no visible symptoms; 0.5 to $2.5=$ mild to moderate symptoms; 3 to $3.5=$ severe symptoms; $4=$ dead. Ratings followed by the same letter are not significantly different from one another $(p=0.05)$. Ratings with different letters are highly significantly different $(p<0.01)$ according to a Tukey's test.

\begin{tabular}{|c|c|c|c|c|c|}
\hline \multirow[b]{2}{*}{ Accession } & \multirow{2}{*}{$\begin{array}{l}\text { Leaf } \\
\text { shape }\end{array}$} & \multirow{2}{*}{$\begin{array}{l}\text { Flower } \\
\text { color }\end{array}$} & \multicolumn{2}{|c|}{ Verticillium response } & \multirow[b]{2}{*}{ Oil composition } \\
\hline & & & Qualitative & Quantitative & \\
\hline$\overline{\mathrm{CMEN}} 585$ & Lanceolate & $\mathrm{W}$ & $\mathrm{R}$ & $0^{\mathrm{z}}$ & $32.8 \%$ Pulegone $24.3 \%$ menthone $11.3 \%$ 1,8-cineole \\
\hline CMEN 501 & Ovate & $\mathrm{P}$ & $\mathrm{R}$ & $0^{\mathrm{z}}$ & $30.4 \%$ Pulegone $25.3 \%$ menthone $11.0 \%$ menthol $5.0 \%$ limonene \\
\hline CMEN 81 & Ovate & $\mathrm{P}$ & $\mathrm{R}$ & $0^{z}$ & $39.2 \%$ Menthone $22.5 \%$ iso-menthone $8.1 \% 1,8$-cineole \\
\hline CMEN 17 & Ovate & $\mathrm{P}$ & $\mathrm{R}$ & $0.3^{\mathrm{a}}$ & $43.4 \%$ Trans-piperitone oxide $19.7 \%$ cis-piperitone oxide $7,0 \%$ 1,8-cineole \\
\hline CMEN 635 & Ovate & $\mathrm{P}$ & $\mathrm{R}$ & $1^{\mathrm{y}}$ & $45.6 \%$ Cis-piperitone oxide $26.6 \%$ piperitenone oxide $5.0 \%$ trans-piperitone oxide \\
\hline CMEN 34 & Ovate & W & $\mathrm{S}$ & $2.0^{\mathrm{x}}$ & $14.9 \%$ Piperitenone oxide $6.97 \%$ limonene \\
\hline CMEN 682 & Ovate & $\mathrm{P}$ & $\mathrm{S}$ & $2.6^{\mathrm{w}}$ & $56.5 \%$ Menthol $14.8 \%$ menthone \\
\hline CMEN 516 & Ovate & $\mathrm{P}$ & $\mathrm{S}$ & $3.5^{\mathrm{v}}$ & $21.9 \%$ Germacrene D $18.6 \%$ trans-piperitone oxide $11.7 \%$ limonene $8.0 \%(\mathrm{Z})$-B-ocimene \\
\hline CMEN 584 & Lanceolate & W & $\mathrm{S}$ & $3.8^{\mathrm{v}}$ & $59.6 \%$ Carvone $12.3 \%$ limonene \\
\hline CMEN 18 & Ovate & $\mathrm{P}$ & I & & $56.4 \%$ Trans-piperitone oxide $7.2 \%$ cis-piperitone oxide $5.8 \% 1,8$-cineole \\
\hline CMEN 19 & Ovate & $\mathrm{P}$ & $\mathrm{S}$ & & \\
\hline CMEN 20 & Ovate & $\mathrm{P}$ & $\mathrm{R}$ & & $13.5 \%$ Pulegone $11.7 \%$ nonanal $7.8 \%$ menthone $7.0 \%$ trans-piperitone oxide $6.6 \%$ limonene \\
\hline CMEN 500 & Ovate & $\mathrm{P}$ & $\mathrm{R}$ & & $34.6 \%$ Pulegone $17.0 \%$ menthone $14.2 \%$ sabinene $6.1 \%$ limonene \\
\hline CMEN 592 & Ovate & $\mathrm{P}$ & $\mathrm{S}$ & & $\begin{array}{l}22.4 \%(\mathrm{E})-\beta \text {-farnesene } 16.0 \% \text { limonene } 12.7 \% \text { nonanal } 11.0 \% \text { B-caryphyllene } \\
7.4 \% \text { Gamma-muurolene }\end{array}$ \\
\hline
\end{tabular}

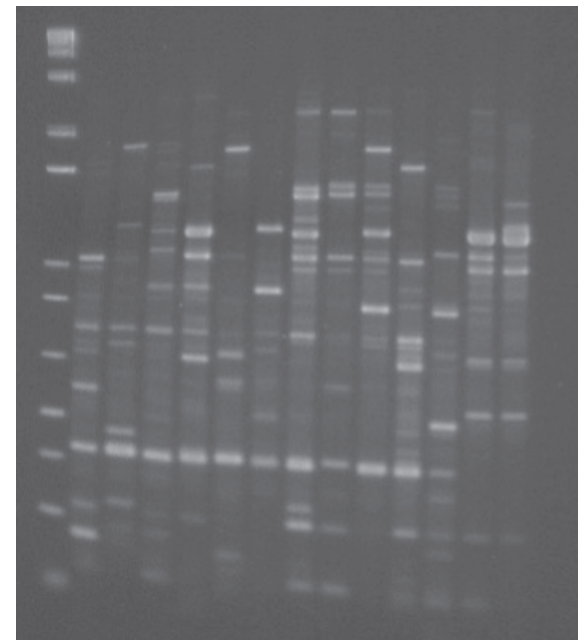

Fig. 1. Example of electrophoretic banding pattern of PCR-amplified DNA fragments produced from RAPD primer OPO20. Lane $1=$ a molecular size marker (1Kb Plus DNA Ladder, Invitrogen). Lanes 2 to $14=\mathrm{CMEN} 17, \mathrm{CMEN} 18$, CMEN 19, CMEN 20, CMEN 34, CMEN 516, CMEN 592, CMEN 500, CMEN 501, CMEN 635, CMEN 682, CMEN 585, and CMEN 584, respectively.

postinoculation. Symptoms ranged from mild horizontal curling of apical leaves to complete necrosis. Nine accessions, selected as representing extremes of inoculation response and other traits of interest, were then screened more rigorously, using the quantitative rating scale of 0 to 4 (Table 2). Results of screenings conducted with the GFP strain were highly consistent with those obtained using the wild type Verticillium strain: the four accessions given 0 to 1.0 ratings in the second trial had all received $\mathrm{R}$ ratings in the first trial, while accessions given ratings 2.0 and above in the second trial all had $\mathrm{S}$ ratings in the first trial (Table 2). Overall, CMEN 585, CMEN 17, CMEN 501, and CMEN 81 were the most resistant, and CMEN 584 and CMEN 516 were the most consistently susceptible accessions.

Symptom development varied considerably among susceptible accessions. For example, by 4 to 6 weeks postinoculation, CMEN 516 exhibited overall chlorosis of leaf tissue, mild to moderate crescent leafing and little or no stunting, while CMEN 584 was consistently stunted $>50 \%$ compared to controls and had substantial crescent leaf symptoms. Both CMEN 516 and CMEN 584 primary stems had died by the time final observations were recorded. However, asymptomatic shoot growth was sometimes seen emerging at the soil surface after complete death of primary stems above the soil line, indicating that at least some portion of these plants survived and escaped or recovered from fungal infection.

Similarly, Verticillium-resistant accessions showed differences in response to fungal inoculation. CMEN 585 occasionally had mild to moderate horizontal curling of apical leaves about 4 weeks postinoculation, followed by production of asymptomatic leaves. CMEN 17 commonly displayed shortened internodes and mild horizontal leaf curl about 4 weeks postinoculation, followed by apparent recovery. CMEN 501 and CMEN 81 rarely displayed any disease symptoms.

For RAPD analysis (Fig. 1), 14 oligonucleotide primers produced a total of 63 informative bands. The number of bands shared by any pair of accessions ranged from 16 to 0 : for example, CMEN 584 had 16 bands in common with CMEN 585 and none in common with five of the accessions (Table 3 ). The Jaccard similarity indices ranged from a high of 0.7619 (CMEN 584 vs. CMEN 585) to a low of 0 (e.g., CMEN 584 vs. CMEN 682) (Table 3). A UPGMA tree had 5 nodes with bootstrap support of $50 \%$ or better (Fig. 2). CMEN 585 and CMEN 584 formed a group that was highly distinct from, and sister to, the other accessions.

The genome sizes of $M$. longifolia accessions CMEN 584 and CMEN 585 were determined to be $4 \mathrm{C}=1.75 \mathrm{pg}(1 \mathrm{C}=440 \mathrm{Mbp})$ and $4 \mathrm{C}=1.64 \mathrm{pg}$ $(1 \mathrm{C}=410 \mathrm{Mbp})$, respectively (Lynda Hanson, pers. comm.). The genome size of CMEN 17 was estimated to be $4 \mathrm{C}=1.57 \mathrm{pg}(1 \mathrm{C}=385 \mathrm{Mb})$ (Bennett and Leitch, 2005).

\section{Discussion}

Our examination of 14NCGR accessions of M. longifolia detected considerable phenotypic

Table 3. Jaccard similarity coefficient matrix. Values above the diagonal are the number of bands shared by each pair of accessions. Values below the diagonal are Jaccard similarity coefficients.

\begin{tabular}{|c|c|c|c|c|c|c|c|c|c|c|c|c|c|}
\hline & CMEN 17 & CMEN 18 & CMEN 19 & CMEN 20 & CMEN 34 & CMEN 516 & CMEN 592 & CMEN 500 & CMEN 501 & CMEN 635 & CMEN 682 & CMEN 585 & CMEN 584 \\
\hline CMEN 17 & & 9 & 12 & 7 & 7 & 9 & 8 & 3 & 4 & 7 & 3 & 2 & 0 \\
\hline CMEN 18 & 0.4286 & & 8 & 7 & 5 & 9 & 8 & 2 & 2 & 7 & 1 & 1 & 0 \\
\hline CMEN 19 & 0.5217 & 0.3478 & & 11 & 6 & 9 & 10 & 4 & 3 & 8 & 3 & 1 & 0 \\
\hline CMEN 20 & 0.2414 & 0.2800 & 0.4231 & & 7 & 7 & 9 & 3 & 1 & 6 & 0 & 4 & 2 \\
\hline CMEN 34 & 0.3043 & 0.2381 & 0.2400 & 0.2800 & & 5 & 7 & 2 & 4 & 3 & 1 & 1 & 1 \\
\hline CMEN 516 & 0.3750 & 0.4500 & 0.3600 & 0.2500 & 0.2083 & & 8 & 4 & 3 & 5 & 1 & 2 & 1 \\
\hline CMEN 592 & 0.3200 & 0.2857 & 0.3226 & 0.2727 & 0.2414 & 0.2581 & & 9 & 10 & 5 & 2 & 2 & 1 \\
\hline CMEN 500 & 0.0968 & 0.0714 & 0.1290 & 0.0909 & 0.0714 & 0.1379 & 0.2903 & & 7 & 2 & 1 & 1 & 2 \\
\hline CMEN 501 & 0.1290 & 0.0690 & 0.0909 & 0.0278 & 0.1481 & 0.0968 & 0.3226 & 0.2500 & & 4 & 3 & 1 & 2 \\
\hline CMEN 635 & 0.3043 & 0.3684 & 0.3478 & 0.2308 & 0.1304 & 0.2083 & 0.1613 & 0.0714 & 0.1481 & & 2 & 1 & 0 \\
\hline CMEN 682 & 0.1500 & 0.0556 & 0.1429 & 0.0000 & 0.0556 & 0.0476 & 0.0741 & 0.0455 & 0.1429 & 0.1176 & & 0 & 0 \\
\hline CMEN 585 & 0.0588 & 0.0323 & 0.0278 & 0.1176 & 0.0323 & 0.0606 & 0.0500 & 0.0286 & 0.0278 & 0.0667 & 0.0000 & & 16 \\
\hline CMEN 584 & 0.0000 & 0.0000 & 0.0000 & 0.0571 & 0.0333 & 0.0303 & 0.0250 & 0.0606 & 0.0588 & 0.0333 & 0.0000 & 0.7619 & \\
\hline
\end{tabular}




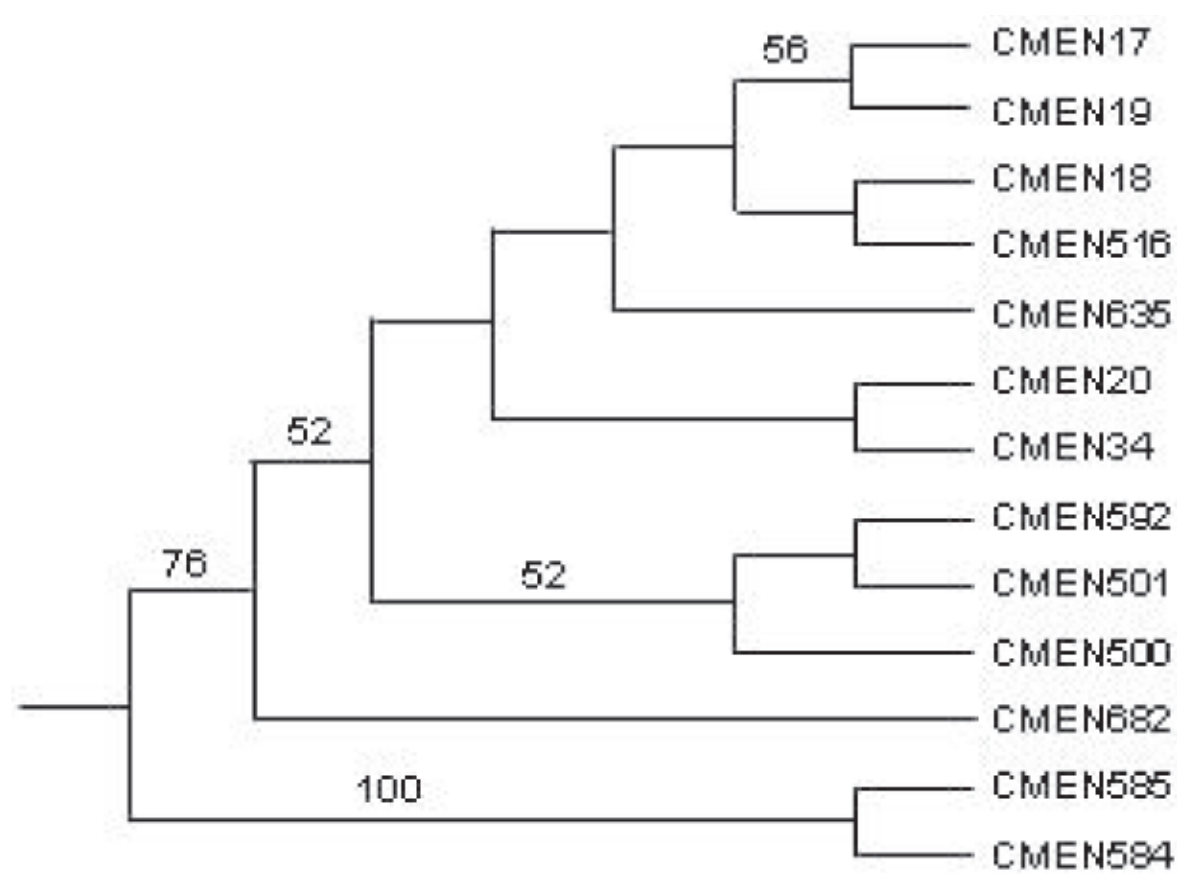

Fig. 2. RAPD marker-based, midpoint-rooted UPGMA dendrogram showing relationships of Mentha longifolia accessions. Numbers above branches are bootstrap values.

and genetic variation. Plant height, flower color, leaf shape and leaf trichome density were obviously variable among the accessions. Variation was noted but not systematically examined in other morphological features such as leaf color, leaf margin type and stem thickness. Although Mentha species are distinguished primarily by their essential oil contents, the range of morphological variation in M. longifolia points to its potential for development as an ornamental species as well as a genetic model system.

Mentha longifolia has been a subject of numerous oil composition studies (Ghoulami et al., 2001; Hefendehl, 1977; Kokkini et al., 1995; Kokkini and Papageorgiou, 1988; Shaiq et al., 2002; Venskutonis, 1996). M. longifolia oil composition has attracted recent attention due to its potential for antimicrobial and antifungal activity (Mimica-Dukic et al., 2003; Abou-jawdah et al., 2002). The present paper adds data on 14 NCGR accessions to the substantial body of knowledge about $M$. longifolia oil composition. CMEN 584 is the only carvone chemotype in the NCGR plant collection; however, other M. longifolia carvone chemotypes have been reported (Hefendehl, 1977; Kokkini et al., 1995).

One major focus of our research with $M$. longifolia is the identification of plants with differential responses to the fungal pathogen $V$. dahliae. Toward that end, all M. longifolia accessions were initially screened with a wild type strain of the fungus. When a GFPtransformed strain became available (Lorang et al., 2001), it was used for subsequent screenings of selected accessions, and of F1 and $\mathrm{F} 2$ populations developed from resistant $\times$ susceptible crosses (results to be presented elsewhere). Trials conducted with the GFP strain of $V$. dahliae produced results consistent with those performed with the wild type strain.
The GFP strain is of interest as a potentially useful tool for the study of the early events of fungal penetration of a plant host (Lorang et al., 2001).

The disease resistance screening showed that some accessions are highly resistant to verticillium wilt and others are highly susceptible. Of the two most resistant accessions, CMEN 501 is a tetraploid and CMEN 81, as a probable hybrid between $M$. longifolia and $M$. spicata (tetraploid), is not likely to be diploid. The two most resistant diploids, CMEN 585 and CMEN 17, sometimes displayed mild disease symptoms followed by asymptomatic growth. The most susceptible $M$. longifolia accessions, CMEN 584 (diploid) and CMEN 516 (chromosome number undetermined), showed differences in symptom development, although the eventual outcome for both was primary stem death. Both genotypes occasionally exhibited secondary growth after death of primary stems, indicating that even when primary stems were completely dead above the soil line, some stem tissue survived and was capable of regeneration. It is possible that part of the disease resistance response in these plants involves blockage of part of the root vascular system in order to sequester the invading fungus. In the field, such a response could allow the plants to escape verticillium disease by growing via secondarily produced shoots and stolons to a noninfested area. A strategy for outgrowing soilborne pathogens is especially important for a perennial species with a primarily asexual mode of reproduction.

Mentha longifolia is recognized as the most phenotypically diverse species of the taxonomically complex Mentha genus (Gobert et al., 2002). These investigators used AFLP markers to analyze 62 Mentha accessions, 6 of which are represented in the present study. They found that M. longifolia grouped as a distinct taxon from other Mentha species, and is most closely related to M. spicata and $M$. suaveolens. The present study, which was aimed only at assessing genetic diversity in $M$. longifolia, demonstrated substantial molecular diversity as detected using RAPD markers. In pairwise comparisons of RAPD markers, only two pairs of accessions (CMEN 17 vs. CMEN 19 , and CMEN 585 vs. CMEN 584) had $>50 \%$ of informative markers in common.

The two South African accessions, CMEN 584 and CMEN 585, are remarkably different in appearance from the others. Both have a tall upright growth habit and lanceolate leaves. In addition, the RAPD marker data set these two accessions apart (Fig. 2, Table 3). However, despite their morphological similarity and the high number of shared RAPD markers, these two accessions were very different from each other in oil composition and verticillium wilt resistance. Our initial results indicate a need to expand the available germplasm collection to include a broader sampling of the South African representatives of $M$. longifolia.

Mentha longifolia is a suitable and valuable species to serve as a model species for mint genetics for several reasons. Of the 14 NCGR accession we examined, 8 are known to be diploid, a favorable feature for genetics and linkage mapping. The $M$. longifolia genome size in the 400 to $500 \mathrm{Mbp}$ range is relatively small, making it a favorable subject for structural and functional genomics studies. The $\mathrm{C}$ values we obtained for CMEN 585 and CMEN 584 are the first reported for South African genotypes of $M$. longifolia. They are comparable to previously published $\mathrm{C}$ value measurements of other NCGR M. longifolia accessions (Gobert et al., 2002). Because of the abundant genetic/phenotypic diversity apparent in the species, crosses between appropriately chosen representatives could be used to study the genetic basis for variation in numerous characters of economic relevance. Examples of trait diversity documented here include plant morphology, disease resistance and oil composition. Given the broad geographic range of $M$. longifolia, the species is likely to contain considerable variation for responses to environmental stress factors as well.

Mentha longifolia is also an intriguing subject for the study of host-pathogen interactions because of its perennial habit, vegetative propagation, and stem morphology. Replication of screening experiments is facilitated because large numbers of cuttings (clones) can be quickly generated from a single plant. Plants can be maintained in a perpetual vegetative growth state under short-day light regimes, minimizing variation due to hormonal differences between flowering and vegetative growth stages. Mentha longifolia is particularly useful for the study of vascular wilt pathogens because of stem morphology: stems are square, and each stem possesses exactly four vascular bundles - one at each corner - making it possible to observe localized disease symptoms and correlate them to pathogen invasion of particular vascular bundles. Thus, the many favorable features of $M$. longifolia make this species a useful diploid system for studies of 
Mentha genetics and genomics, and a vegetatively propagated model organism of potential interest for the study of plant-pathogen interactions in general.

\section{Literature Cited}

Abou-jawdah Y., H. Sobh, and A. Salameh. 2002.Antimycotic activities of selected plant flora, growing wild in Lebanon, against phytopathogenic fungi. J. Agr. Food Chem. 50(11):3208-3213.

Bennett, M.D. and I.J. Leitch. 2005. Nuclear DNA amounts in angiosperms - Progress, problems and prospects. Ann. Bot. 95(1):45-90.

Bunsawat, J., N.E. Elliott, K.L. Hertweck, E. Sproles, and L.A. Alice. 2004. Phylogenetics of Mentha (Lamiaceae): Evidence from chloroplast DNA sequences. System. Bot. 29:959-964.

Burke, C., K. Klettke, and R. Croteau. 2004. Heteromeric geranyl diphosphate synthase from mint: construction of a functional fusion protein and inhibition by bisphosphonate substrate analogs. Arch. Biochem. Biophys. 422(1):52-60.

Chambers, H.L. and K.E. Hummer. 1994. Chromosome counts in the Mentha collection at the USDA-ARS National Clonal Germplasm Repository. Taxon 43:423-432.

Croteau, R. and J. Gershenzon. 1994. Genetic control of monoterpene biosynthesis in mints (Mentha: Lamiaceae), p. 193-229. In: B.E. Ellis, G. Kuroki, and H.A. Stafford (eds.). Genetic engineering of plant secondary metabolism. Plenum Press, New York.

Fagbemi, B.O.B. and J.K. Morton. 1982. Studies on Mentha $\times$ dumetorum Schult. (Labiateae) to confirm its presumed parentage- $M$. aquatica Linn. $\times$ M. longifolia (Linn.) Huds. Rhodora 84:439-445.

Ghoulami, S., A. Il Idrissi, and F. Fkih-Tetouani. 2001. Phytochemical study of Mentha longifolia of Morocco. Fitoterapia 72(5):596-598.

Gobert, V., S. Moja, M. Colson, and P. Taberlet. 2002. Hybridization in the section Mentha (Lamiaceae) inferred from AFLP markers. Amer. J. Bot. 89:2017-2023.

Green, R.J. and J.E. Simon. 1996. Evaluations of
MIRC peppermint and spearmint lines. Min Ind. Res. Council Annu. Proc. 1996.

Germplasm Resources Information Network. 2004. USDA, ARS, National Genetic Resources Program. Germplasm Resources Information Network (GRIN) (Online Database). National Germplasm Resources Laboratory, Beltsville, Md. 14 Dec. 2004. http://www.ars-grin.gov/cor/ mentha/meninfo.html.

Hefendehl, F.W. 1977. Monoterpene composition of a carvone containing polyploidy strain of Mentha longifolia (L.) Huds. Herba Hung. 16(1):39-43.

Hefendehl, F.W. and M.J. Murray. 1976. Genetic aspects of the biosynthesis of natural odors. Lloydia 39:39-52.

Hendriks, H., F.H.L. van Os, and W.J. Feenstra. 1976. Crossing experiments between some chemotypes of Mentha longifolia and Mentha suaveolens. P1. Med. 30:154-162.

Jaccard, P. 1908. Nouvelles recherches sur la distribution florale. Bul. Soc. Vaudoise Sci. Nat. 44:223-270

Kaiser, H., and W. Lang. 1951. Ueber die bestimung des ätherischen oels in drogen. Deutsche Apotheker-Z./Sddeutsche ApothekerZ. 91:163-166.

Kokkini, S. and V.P. Papageorgiou. 1988. Constituents of essential oils from Mentha longifolia growing wild in Greece. Planta Med. 1:59-60.

Kokkini, S., R. Karousou, and T. Lanaras. 1995. Essential oils of spearmint (carvone-rich) plants from the island of Crete (Greece). Biochem. System. Ecol. 23:425-430.

Lorang, J.M., R.P. Tuori, J.P. Martinez, T.L. Sawyer, R.S. Redman, J.A. Rollins, T.J. Wolpert, K.B. Johnson, R.J. Rodriguez, M.B. Dickman, and L.M. Ciuffetti. 2001. Green fluorescent protein is lighting up fungal biology. Appl. Environ. Microbiol. 67(5):1987-1994.

Mahmoud, S.S. and R.B. Croteau. 2001. Metabolic engineering of essential oil yield and composition in mint by altering expression of deoxyxylulose phosphate reductoisomerase and menthofuran synthase. Proc. Natl. Acad. Sci. USA. 98:8915-8920.
Mahmoud, S.S., M. Williams, and R.B. Croteau. 2004. Cosuppression of limonene-3-hydroxylase in peppermint promotes accumulation of limonene in the essential oil. Phytochemistry 65:547-554.

Mimica-Dukic, N., B. Bozin, M. Sokovic, B. Mihajlovic, and M. Matavulj. 2003. Antimicrobial and antioxidant activities of three Mentha species essential oils. Planta Med. 69(5):413-419.

Murray, M.J. 1960. The genetic basis for a third ketone group in Mentha spicata L. Genetics 45:931-937.

Shaiq A.M., M. Saleem, W. Ahmad, M. Parvez, and R. Yamdagni. 2002. A chlorinated monoterpene ketone, acylated beta-sitosterol glycosides and a flavanone glycoside from Mentha longifolia (Lamiaceae). Phytochemistry 59(8):889-895.

Torres A.M., Weeden N.F., and A. Martin. 1993. Linkage among isozyme, RFLP, and RAPD markers in Vicia faba. Theor. Appl. Genet. 85:937-945.

Tucker,A.O. and D.E. Fairbrothers. 1990. The origin of Mentha $\times$ gracilis (Lamiaceae). I. Chromosome numbers, fertility, and three morphological characters. Econ. Bot. 44:183-213.

Tucker, A.O. and H.E. Chambers. 2002. Mentha canadensis L.(Lamiaceae): Arelictamphidiploid from the lower tertiary. Taxon 51:703-718.

Tucker, A.O., H. Hendriks, R. Bos, and D.E. Fairbrothers. 1991. The origin of Mentha $\times$ gracilis (Lamiaceae). II. Essential oils. Econ. Bot. 45:200-215.

Tucker, A.O. and R.F.C. Naczi. 2005. Mentha: An overview of its classification and relationships. In: B.M. Lawrence (ed.). Mints: The genus Mentha. Taylor \& Francis, London (in press).

Udo, S., S. Shimizu, and N. Ikeda. 1962. Studies on the origin of Mentha piperita L. Sci. Rpt. Fac. Agr. Okayama Univ. 20:1-12.

Venskutonis, P.R. 1996. A chemotype of Mentha longifolia $\mathrm{L}$. from Lithuania rich in piperitenone oxide. J. Essent. Oil Res. 8:91-95.

von Rudloff, E. 1969. Scope and limitations of gas chromatography of terpenes in chemosystematics studies. Rec. Adv. Phytochem. 2:127-162. 